\title{
Cognitive model of caregiving in psychosis
}

\author{
Elizabeth Kuipers, Juliana Onwumere and Paul Bebbington
}

\section{Background}

There is a long history of research into the attributes of carers of people with psychosis, but few interventions target their distress or their difficulties.

\section{Aims}

To describe an empirically based model of the relationships of those caring for people with psychosis to inform clinical and theoretical advances.

\section{Method}

We developed a model of informal carer relationships in psychosis, based on an integration of the literature elaborating the concept of expressed emotion. The model accounts for divergent outcomes of three relationship types: positive, overinvolved and critical/hostile relationships.

\section{Results}

Good evidence supports a number of hypotheses concerning the origin and maintenance of these relationship outcomes, which relate to specific differences in carer attributions, illness perceptions, coping behaviour, social support, distress, depression and low self-esteem predicted by our model. We propose that interventions aimed at modifying the specific maintenance factors involved in the different styles of relationships will optimise therapeutic change both for service users with psychosis and for their carers.

\section{Conclusions}

Family work in psychosis, which improves relationships through problem-solving, reduces service user relapse. It is now time to consider theory-based interventions focused on improving carer outcomes.

\section{Declaration of interest}

None.
'Family members are as much victims of severe mental disorders as patients themselves' (McFarlane \& Cook: p. 196) ${ }^{1}$

Research on informal carers dates back to the 1950s, at which time the bed numbers in asylums in the UK and USA first began to decline. There was thus a new requirement in the UK for informal carers (usually relatives) to be involved in the day-to-day care of people with serious mental health problems. The first empirical research linking family atmosphere and the outcome of psychosis was initiated soon afterwards, ${ }^{2}$ and the first attempts to modify outcome by family intervention followed. ${ }^{3,4}$ The early interventions were based on general principles, and lacked a detailed understanding of the particular psychological disturbances associated with caring roles in psychosis. We now know considerably more about the relationships between people with psychosis and their carers. ${ }^{5}$ Carers' appraisals of their situation and of the resources they have to cope with it are more crucial to both carer and service user outcomes than the apparent severity or scope of the problems faced. ${ }^{6}$ Although all carers face potential stresses, their appraisal of the situation and how they try to deal with it contribute to the well-being of service users and should be key targets for intervention. It seems timely to integrate this new information and relate it to interventions that target improvement in carer well-being as a primary focus. Although such a model may also apply to other disorders, the evidence presented here concerns those caring for people with psychosis.

\section{Definition}

Carers of people with psychosis are usually family members, mainly parents or partners. ${ }^{7}$ There is an ongoing issue about how carers define themselves (e.g. 'carer', 'parent' or 'supporter'), but this does not affect the undoubted strains of the role. In our view, caring for people with psychiatric problems is not generally a matter of choice. ${ }^{8}$ It is often impossible to walk away, although carers vary in their degree of acceptance of the role. We have identified that it is 'an inherently unequal role; the person doing the caring has more responsibility, and has more to do than the person being cared for, who is to some extent dependent' (Kuipers \& Bebbington: p. 217). ${ }^{9}$ There are other definitions. The mental health charity Mind (www.mind.org.uk/help/people_groups_and_ communities/how_to_access_services-information_for_carers\#whois) states that 'you are a carer if you provide help and support to someone with a mental health problem and/or a physical disability.' They go on to distinguish between friends and family who provide unpaid care and paid professionals, and underline that the caring relationship can be mutual. The website of the Princess Royal Trust for Carers (not restricted to mental health carers) defines a carer as 'someone who, without payment, provides help and support to a partner, child, relative, friend or neighbour, who could not manage without their help' (www.carers.org).

\section{Impact of care}

Caring for a family member with psychosis is demanding, often prolonged, and associated with increased levels of stress and distress. ${ }^{6,9-11}$ Recent evidence suggests that as many as a third of carers meet criteria for post-traumatic stress disorder. ${ }^{12}$ Carers also experience a great sense of loss, comparable to levels recorded in physical bereavement. ${ }^{13}$ The first carer study evaluated the impact on the wives of men discharged from psychiatric hospital. ${ }^{14}$ This was the start of research into the so-called 'burden' of such care. As can be seen from the use of this terminology, caring was felt to be a solely negative experience, and the early researchers did not ask about positive effects. In these early stages burden was defined as 'the difficulties felt by the family of a psychiatric patient' (Pai \& Kapur: p. 334$)^{15}$ or more broadly as 'the effect of the patient upon the family' (Goldberg \& Huxley: p. 127). ${ }^{16}$

\section{Expressed emotion}

Pioneering research made it clear that, although family involvement could be helpful, some reactions - particularly if critical or overinvolved - were associated with subsequent relapse of the 
service user. $^{17}$ We have shown, in an analysis of prospective studies, that high levels of this expressed emotion (EE) are a reliable predictor of patient outcomes in schizophrenia: overall, the relapse rate for those returning to families with low EE was $21 \%$ compared with a $50 \%$ relapse rate in families with high EE. ${ }^{18}$ Further studies confirmed that 'burden', particularly as assessed by the carers themselves, was strongly correlated with high EE. It was also related to poor carer outcomes such as stress, distress and low self-esteem, and to less effective, avoidant coping, even at first episode. ${ }^{19,20}$

\section{Attributions}

Another strand of research originated from Weiner's theory of attribution, emotion and behaviour: whether events were good or bad, and why they happened. ${ }^{21}$ An attributional model of $\mathrm{EE}$, including the concepts of intention and control, was first put forward by Hooley. ${ }^{22}$ Since then it has become clear that high-criticism carers are more likely to make 'controllable' and 'personal' attributions, both in psychosis and in other disorders such as diabetes. ${ }^{23,24}$ In other words, if carers are critical, their attributions are more likely to lead to assertions that patients are substantially in control of - and therefore to blame for negative events. This in turn relates to greater carer distress and negative evaluations of the caring role. Carers' appraisals of and reactions to their role not only affect their own well-being, but also may improve or impede recovery in those they care for. ${ }^{18}$ More recent evidence suggests a mechanism for this: service users are able to perceive criticism from their carers accurately, ${ }^{25-27}$ and perceptions of carer criticism have in turn been linked to poorer service user functioning. ${ }^{27}$

\section{Illness perceptions}

Other methods of evaluating the caring role have developed from Leventhal et al's conception of illness perceptions. ${ }^{28}$ As in physical ill health, ${ }^{29}$ carer illness perceptions and the consequent behavioural decisions are more likely to predict carer outcomes than illness severity. This has been shown to be equally relevant for informal caring in psychosis; ${ }^{30,31}$ if carers feel that they are not in control of their relative's illness and that it will last a long time, they experience more stress and depression and have more negative views of the impact of care. Moreover, if carers and service users disagree about these illness perceptions, carers tend to have lower mood and self-esteem. ${ }^{32}$ Such disagreements tend to be observed more in high-EE relationships. ${ }^{33}$

\section{Positive caregiving experiences}

In the past decade, as part of an attempt to explore caregiving within a broader framework, attention has been given to the positive aspects of the caregiving relationship and their links with carer and service user outcomes. ${ }^{34,35}$ Thus, we know that many carers report positive caregiving experiences, including feelings of satisfaction and improved self-esteem. ${ }^{36,37}$ Further, carer warmth can serve as a protective factor against relapse, $2,38,39$ particularly in some Black and minority ethnic groups. ${ }^{40,41}$

\section{Coping}

There is now some literature on the coping responses optimal for carers of people with psychosis. ${ }^{42-44}$ This is based on the ideas of Lazarus \& Folkman that coping itself depends on accurate appraisal of situations, on one's resources and on how these are marshalled. ${ }^{45}$ In psychosis, avoidant coping (a style of emotional response characterised by 'hoping problems will go away') may be useful for problems that resolve naturally, but not with more enduring or worsening problems. Active and proactive strategies seem better at reducing the impact on levels of carer burden, even in the early stages of illness. ${ }^{19,43,46}$ These sorts of strategies are usually shaped and encouraged as part of family interventions. ${ }^{47,48}$

\section{Social support}

The stigma and shame associated with mental ill health can lead to a significant reduction in social networks, even for carers. ${ }^{49,50}$ The importance of social support in reducing distress and encouraging more proactive coping in carers has been confirmed. ${ }^{51,52}$

\section{Intervention studies}

Carer outcomes have been primary objectives in few intervention studies. The research impetus in relation to caregiving in psychosis has so far been towards improving service user outcomes. This has had some success. Family intervention in psychosis, involving the whole family in negotiated problem-solving, reappraisal and reattribution of difficulties, and emotional processing of the loss and grief, has shown some improvements in carer 'burden. ${ }^{53}$ However, most improvement has been in reducing service user relapses. ${ }^{54,55}$ In the small number of studies focusing on carer outcomes, ${ }^{56,57}$ only two have demonstrated a positive impact on carer well-being. ${ }^{5,59}$ However, this is not surprising, as there is evidence that carer well-being relates closely to service user outcome. $^{5}$

\section{Cognitive model of caregiving}

On the basis of a growing and complex literature, we propose that caregiving appraisals and reactions in psychosis can be usefully described in a model as shown in Fig. 1. It is these appraisals that engender carer cognitive and affective reactions, and lead to a range of carer behaviours towards service users and towards services, and to different carer outcomes. The pathways and their interactions constitute testable hypotheses, and suggest that

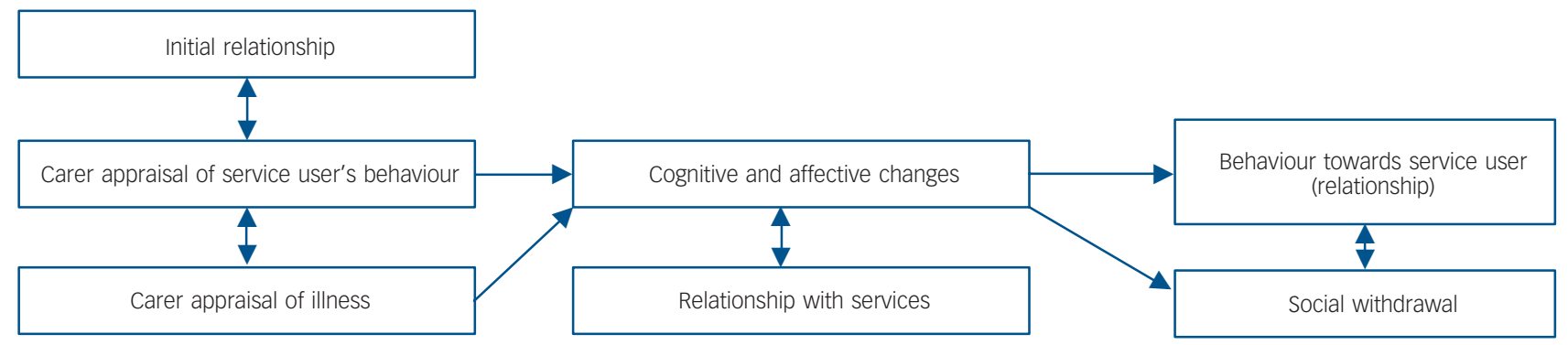

Fig. 1 Cognitive model of carer responses in psychosis. 
specific interventions targeting these appraisals and their maintenance factors might improve outcomes. Most existing research is of analyses restricted to a single domain. Our model integrates this prior research for two linked purposes: to set up testable hypotheses of interactions, and to develop interventions, the evaluation of which will then form collateral tests of the original model. The research to test these hypotheses has yet to be done. It is hoped that both the model and the interventions that might arise from it will be developed further.

Given the overall model, we suggest further that three different styles or types are at present supported by the evidence, interpreted in the light of clinical experience of intervention with families dealing with psychosis. Although our typology of the characteristics of caregiving can never be exact, it is based in empirical research, and we think it will be of use in shaping interventions to the needs of caregivers. Analysis in terms of the three styles will, we propose, maximise the likelihood of change and of change being sustained. They provide testable hypotheses to evaluate both the maintenance effects and the interventions themselves.

\section{Positive relationships}

The first type of caregiving is represented by those who, for whatever reason, previously had a positive relationship with the person developing psychosis (Fig. 2). Before the illness, relations were warm and communicative, and interactions were positive. The carer thus sees the service user as a person, not just as a compendium of problems. The problems that do emerge are then more likely to be understood as unusual, not as part of normal 'adolescent' bad behaviour, and therefore as something requiring a different reaction. The service user is seen as needing care and help, while respect for their autonomy is nonetheless maintained. Because problems are recognised, even if the cause is not yet identified, these carers are able to ask for help, both from formal sources and from their social network, in a manner that is likely to

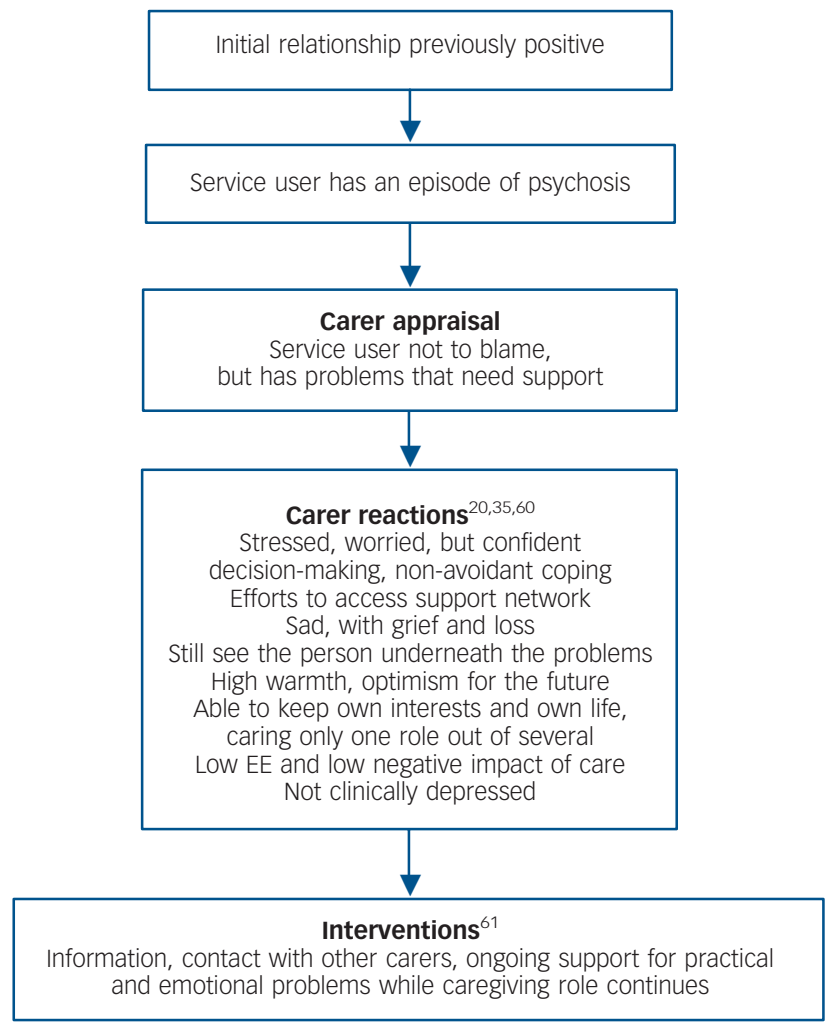

Fig. 2 Positive relationships. EE, expressed emotion. be effective and sustainable. They thus do not become isolated. Moreover, when they are offered help, they are more likely to accept it and to act upon it. They are able to make decisions confidently. ${ }^{60}$ Their key appraisals are positive: that the care recipient is not to blame but needs help for their problems, ${ }^{35}$ and that these might be soluble if carer and recipient work together.

Such carers still require intervention. ${ }^{61}$ At the very least they need information, support, respite and help in integrating a caring role into other roles in their lives. They are more likely to continue with their other roles such as work and childcare, not abandoning them to care only for the service user. Although these carers may be stressed and sad, they are rarely clinically depressed. They respond positively to offers of help from services, and they may themselves be particularly helpful to other carers. However, there is a danger that services may ignore this group of carers, feeling that they are coping well, and thus fail to be responsive or proactive.

\section{Emotionally overinvolved relationships}

Emotional overinvolvement in those caring for people with psychosis is a strong marker of poor current psychological and physical health. The evidence suggests that it may also be an indicator of poor future health. ${ }^{62}$ Emotional overinvolvement has strong positive links with feelings of loss, ${ }^{13}$ self-blame and guilt about being responsible for the person's illness. ${ }^{63-65}$ Carers with this style are more likely to be parents, as this is a parenting style perfectly appropriate for younger children. Relationships have typically been good but seem rooted in the past. Such carers will talk about how 'wonderful' or 'beautiful' the person used to be when a small child. The loss and transformation of this child into, first, a difficult adolescent, and then into someone with mental health problems, is accompanied by understandable grief and distress. The appraisal at this stage is that the person is not to blame, but needs to be buffered against all difficulties. ${ }^{35}$ This becomes the carer's life work. It is often taken up at the cost of other roles, including employment.

We propose that interventions need to focus on finding positives about service users as they are now, not just as they were in the past. Such carers also need permission to take back their own lives, to address issues related to their own health and wellbeing, and to have perspectives beyond those related to the caring role. Because caring for people with mental health problems can be both isolating and stigmatising, these people are likely to have lost their own support network. Thus it can be useful to help them re-engage with confidantes and social support, either through other carers, or informally.

Such carers are often those who continue to search for a cure. This would bring back the potential of the 'lost child'. Anything less than this can feel as if they are giving up, or not caring enough. Offering information and advice to these carers may be unproductive, as the mere provision of facts will not help. Instead, it is necessary to foster a caring style that assists the care recipient to become more independent, thereby reducing the buffering role of the carer, while encouraging carers to re-engage with their own plans and interests. A problem-solving approach may reveal that the person with psychosis is still capable of adult roles. It can then be used as the basis for gradually giving these roles back to the person. This can parallel encouragement for carers to find other roles for themselves. Offers of respite and breaks can be particularly helpful to reduce stress and to allow other interests to develop (Fig. 3).

\section{Critical and hostile relationships}

Critical and hostile attitudes are the more common negative reactions to the stresses of the caring role in psychosis, and can 


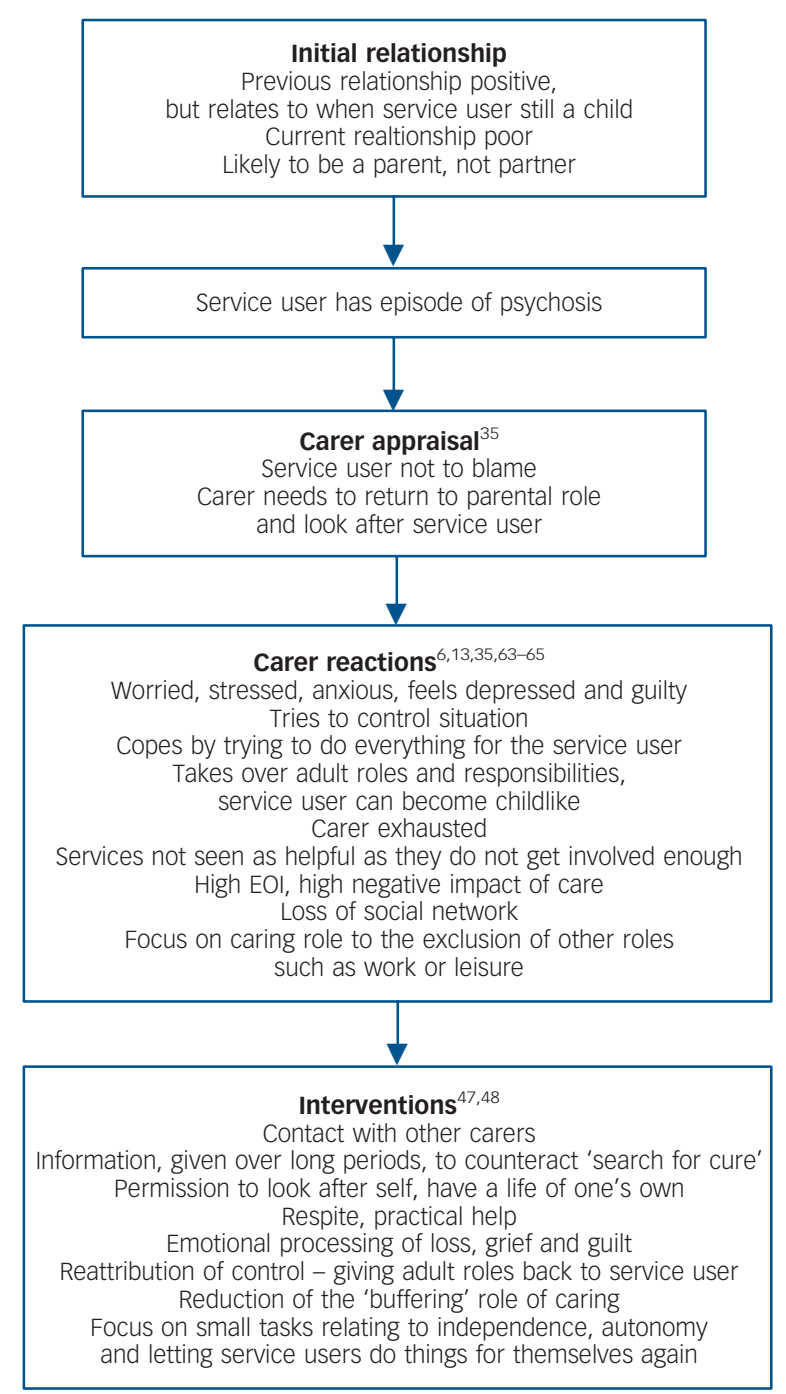

Fig. 3 Overinvolved relationships. EOI, emotional overinvolvement.

be found in all types of carer, whether parents, partners, children or siblings. Earlier relationships between service users and carers will often have been poor, with the service user perhaps displaying a long history of adolescent turmoil and poor performance at school. Substance misuse on the part of the service user is also likely, whether of alcohol, cannabis, other street drugs or all of these. Although problems will be noticed, they will tend to be seen as normal but difficult behaviour patterns, not as signs of mental ill health. In this relationship style a longer duration of untreated psychosis is likely, associated with poor role performance. Because of the poor relationship, the service user is less likely to confide in the carer, and more likely to deny problems or to refuse to discuss them. The initial presentation may therefore be delayed, with more severe symptoms and a more dramatic entry to services. Carers at this stage can be devastated by the involvement of mental health services, with all the associated stigma and shame. Carer appraisals are then likely to involve blaming the service user's character or behaviour, particularly if the latter involves drug use. Carers themselves will not feel to blame, or that they can do much that will make a difference. The onus will usually be on the service user to 'get better', by taking medication and other treatment, and by taking some responsibility for their progress. This is when criticism and hostility develop. In this relationship type, carers themselves are likely to be angry, upset, anxious and depressed. They may have low self-esteem, and feel that nothing they can do will make any difference. They will exert pressure on services to be helpful, and on the service user to improve by their own efforts. Such carers will often try to cope by using emotional strategies such as avoidance - waiting for things to get better by themselves.

Interventions for critical carers may not always be possible. The more rejecting carers may not take on the caring role at all, may abandon it during the initial phase of illness, or may not engage productively with services. For those who remain, the provision of information can be crucial. These are the carers who may respond best to information and advice. Even so, the information will probably need to be given more than once, over quite long periods, as it will be new and often unwelcome. Unwelcome information and disconfirmation is never processed and acted on as easily as confirmatory information. Sharing information with a group of carers, answering questions and discussing answers, is often better and more easily understood than information given in a didactic format.

An important part of intervention for this group of carers is the reattribution of control and consequences, by suggesting to them that service users are not totally in control of their thinking and behaviour, as it is now strongly influenced by symptoms of psychosis. ${ }^{66}$ It is a useful strategy to discuss directly with carers and service users the impact of such symptoms as voices, and how carers can help in dealing with them. Negotiated problemsolving is another key focus, with both parties encouraged to change a small part of their behaviour as a way of finding out whether this can improve things.

Negative communication patterns may be particularly unhelpful as they are associated with negative affect in patients. ${ }^{20,67}$ Carers may be unaware of this. Demonstrating and then modifying the impact of such communications can be another useful goal of family therapy sessions. Finally, an appreciable proportion (around a third) of carers in these critical relationships have clinical levels of depression. This is associated with more avoidant coping, low self-esteem and an understandable pessimism..$^{20}$ We recommend working directly on this either in family sessions or individually with carers. This should include a focus on negative cognitions as well as on behavioural activation and activity scheduling (Fig. 4).

\section{Discussion}

Consistent with an increasing trend to categorise subgroups of carers, ${ }^{61,68}$ we have developed a testable model that could be used in future research: for instance, to test the maintaining factor of avoidant coping and resultant carer distress. We have also provided a typology of relationships between people with psychosis and their informal carers. In some families there will have been difficult problems including previous neglect and abuse. ${ }^{69}$ These kinds of families will not usually be in caring roles, by definition. In families providing care, not all carers will fit these types of caregiving. Families have widely varying structures, relationships and histories. In some families, for instance, carers will have opposing views; parents can show contrary reactions, and find themselves arguing with each other as well as with the service user. Over time, initial reactions of shock, bewilderment and denial of mental health difficulties can settle into adaptive and productive relationships that underwrite good recovery. For other families, things do not improve: there are further episodes, and problems continue or indeed multiply. The stress of the caregiving role can then take its toll in depression, anxiety, 


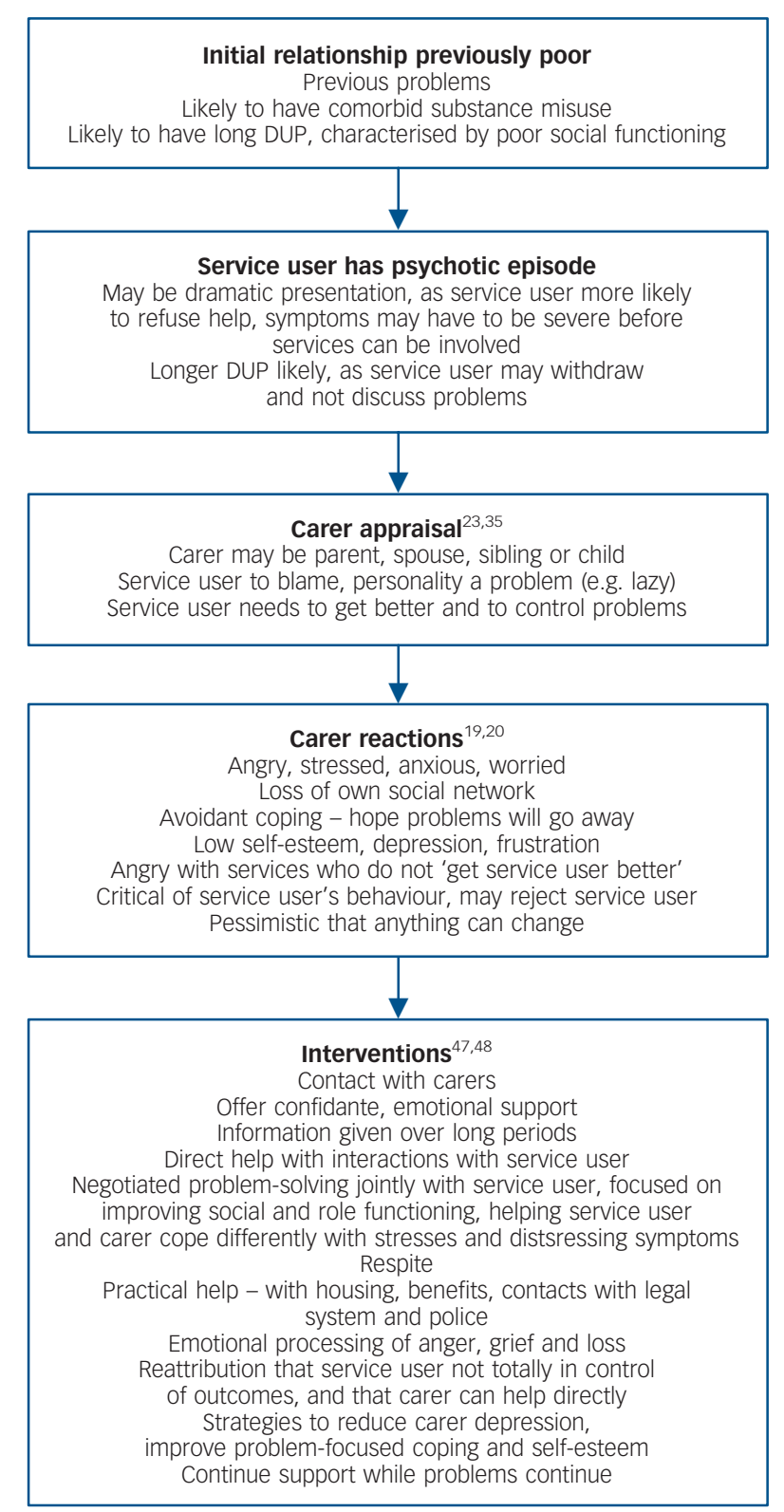

Fig. 4 Critical and hostile relationships. DUP, duration of untreated psychosis.

exhaustion, exasperation with the service user and frustration with inadequate services. The result may be that no one in the family is managing, and all that its members share is pessimism and cynicism. Families may also become 'stuck' at these initial stages, finding it impossible to adapt to the current reality or to new problems, because this feels like a defeat, giving up. More problems then occur, confirming that the only solution is the struggle to get better treatment.

However, more recently positive aspects of caregiving have been identified. ${ }^{36,37}$ When asked, long-standing carers may be more optimistic than those caring for people at an early stage of their illness. ${ }^{31}$ Families who pass through the initial shock and stigma may find a way of seeing caregiving as enriching. Recent studies have reported that recovery after an initial episode is more rapid in those with positive relationships and family support. ${ }^{1,34}$ Our own intervention study showed that service users with carers demonstrated better outcomes from cognitive-behavioural therapy or family intervention. ${ }^{70}$ These findings are a welcome change from the more negative views of caregiving, and are consistent with a growing body of research suggesting service users obtain better outcomes when they have carers. However, it is not yet clear exactly how carers exert positive influences, nor whether these effects also relate to carer outcomes. Both topics require investigation, but there are indications that good problem-solving skills in patients and carers may have a role. ${ }^{71}$

Improving carer outcomes requires a theoretical and practical understanding of the mechanisms that develop and maintain carer distress, together with those that optimise the positive aspects of the role. Although carers remain a resource of the greatest importance in the effective management of psychosis, ${ }^{72}$ they very much merit the attention of clinicians in their own right.

Elizabeth Kuipers, PhD, FBPS, AcSS, Juliana onwumere, PhD, DClinPsy, King's College London, Department of Psychology, Institute of Psychiatry, London; Paul Bebbington, PhD, FRCP, FRCPsych, Department of Mental Health Sciences, Paul Bebbington, PhD, FRCP,
University College London, UK

Correspondence: Professor Elizabeth Kuipers, PO 77, Institute of Psychiatry, London SE5 8AF, UK. Email: elizabeth.kuipers@kcl.ac.uk

First received 27 Jul 2009, final revision 7 Jan 2010, accepted 19 Jan 2010

\section{Funding}

E.K. has received funding for some clinical sessions by the National Institute for Health Research (NIHR) Biomedical Research Centre for Mental Health at the South London and Maudsley NHS Foundation Trust, and Institute of Psychiatry, King's College London.

\section{References}

1 McFarlane WR, Cook WL. Family expressed emotion prior to onset of psychosis. Fam Process 2007; 46: 185-97.

2 Brown GW, Birley JLT, Wing JK. Influence of family life on the course of schizophrenic disorders: a replication. Br J Psychiatry 1972; 121: 241-58.

3 Leff J, Kuipers L, Berkowitz R, Eberlein-Vries R, Sturgeon D. A controlled trial of social intervention in the families of schizophrenic patients. Br J Psychiatry 1982; 141: 121-34.

4 Falloon IRH, Boyd JL, McGill CW, Razani J, Moss HB, Gilderman AM. Family management in the prevention of exacerbations of schizophrenia: a controlled study. N Engl J Med 1982; 306: 1437-40.

5 Askey R, Holmshaw J, Gamble C, Gray R. What do carers of people with psychosis need from mental health services? Exploring the views of carers, service users and professionals. J Fam Ther 2009; 31: 310-31.

6 Scazufca M, Kuipers E. Links between expressed emotion and burden of care in relatives of patients with schizophrenia. Br J Psychiatry 1996; 168: 580-7.

7 Lauber C, Eichenberger A, Luginbuhl P, Keller C, Rossler W. Determinants of burden in caregivers of patients with exacerbating schizophrenia. Eur Psychiatry 2003; 18: 285-9.

8 Kuipers E. Needs of carers. In Measuring Mental Health Needs (2nd edn) (ed GH Thornicroft): 342-62. Gaskell, 2001.

9 Kuipers E, Bebbington P. Research on burden and coping strategies in families of people with mental disorders: problems and perspectives. In Families and Mental Disorder: From Burden to Empowerment (eds N Sartorius, J Leff, JJ Lopez): 217-34. Wiley, 2005.

10 Brown S, Birtwistle J. People with schizophrenia and their families. Fifteen-year outcome. Br J Psychiatry 1998; 173: 139-44.

11 Roick C, Heider D, Bebbington PE, Angermeyer MC, Azorin JM, Brugha TS, et al. Burden on caregivers of people with schizophrenia: comparison between Germany and Britain. Br J Psychiatry 2007; 190: 333-8.

12 Barton $\mathrm{K}$, Jackson $\mathrm{C}$. Reducing symptoms of trauma among carers of people with psychosis: pilot study examining the impact of writing about caregiving experiences. Aust N Z J Psychiatry 2008; 42: 693-701.

13 Patterson $\mathrm{P}$, Birchwood $\mathrm{M}$, Cochrane R. Expressed emotion as an adaptation to loss: prospective study in first-episode psychosis. Br J Psychiatry 2005; 187 (suppl 48): s59-64.

14 Yarrow MR, Schwartz CG, Murphy HS, Deasy L. The psychological meaning of mental illness in the family. J Soc Issues 1955; 11: 12-24. 
15 Pai S, Kapur RL. The burden on the family of a psychiatric patient: development of an interview schedule. Br J Psychiatry 1981; 138: 332-5.

16 Goldberg D, Huxley P. Mental Illness in the Community. Tavistock, 1980.

17 Rutter M, Brown GW. Reliability and validity of measures of family life and relationships in families containing a psychiatric patient. Soc Psychiatry 1966 1: 38-53.

18 Bebbington $\mathrm{P}$, Kuipers $\mathrm{L}$. The predictive utility of expressed emotion in schizophrenia - an aggregate analysis. Psychol Med 1994; 24: 707-18.

19 Raune D, Kuipers E, Bebbington PE. Expressed emotion at first-episode psychosis: investigating a carer appraisal model. Br J Psychiatry 2004; 184: 321-6.

20 Kuipers E, Bebbington P, Dunn G, Fowler D, Freeman D, Watson P et al. Influence of carer expressed emotion and affect on relapse in non-affective psychoses. Br J Psychiatry 2006; 188: 173-9.

21 Weiner B. An attributional theory of achievement-motivation and emotion. Psychol Rev 1985; 92: 548-73.

22 Hooley JM. Expressed emotion - a review of the critical literature. Clin Psychol Rev 1985; 5: 119-39.

23 Barrowclough C, Hooley JM. Attributions and expressed emotion: a review. Clin Psychol Rev 2003; 23: 849-80.

24 Wearden AJ, Ward J, Barrowclough C, Tarrier N, Davies R. Attributions for negative events in the partners of adults with type I diabetes: associations with partners' expressed emotion and marital adjustment. $\mathrm{Br} J \mathrm{Health}$ Psychol 2006; 11: 1-21.

25 Bachmann S, Bottmer C, Jacob S, Schroder J. Perceived criticism in schizophrenia: a comparison of instruments for the assessment of the patient's perspective and its relation to relatives' expressed emotion. Psychiatry Res 2006; 142: 167-75

26 Cutting LP, Aakre J, Docherty NM. Schizophrenia patients' perceptions of stress, expressed emotion attitudes, and sensitivity to criticism. Schizophr Bull 2006; 32: 743-50.

27 Onwumere J, Kuipers E, Bebbington P, Dunn G, Freeman D, Fowler D, et al Patient perceptions of caregiver criticism in psychosis links with patient and caregiver functioning. J Nerv Ment Dis 2009; 197: 85-91.

28 Leventhal H, Nerenz DR, Steele DF. Illness representations and coping with health threats. In Handbook of Psychology and Health (eds A Baum, SE Taylor, J Singer): 517-54. Erlbaum, 1984.

29 Hagger MS, Orbell S. A meta-analytic review of the common-sense model of illness representations. Psychol Health 2003; 18: 141-84.

30 Lobban F, Barrowclough C, Jones S. Assessing cognitive representations of mental health problems. II. The illness perception questionnaire for schizophrenia: relatives' version. Br J Clin Psychol 2005; 44: 163-79.

31 Onwumere J, Kuipers E, Bebbington P, Dunn G, Fowler D, Freeman D, et al. Caregiving and illness beliefs in the course of psychotic illness. Can J Psychiatry 2008; 53: 460-8

32 Kuipers $E$, Watson $P$, Onwumere J, Bebbington $P$, Dunn G, Weinman J, et al. Discrepant illness perceptions, affect and expressed emotion in people with psychosis and their carers. Soc Psychiatry Psychiatr Epidemiol 2007; 42 277-83

33 Lobban F, Barrowclough C, Jones S. Does expressed emotion need to be understood within a more systemic framework? An examination of discrepancies in appraisals between patients diagnosed with schizophrenia and their relatives. Soc Psychiatry Psychiatr Epidemiol 2006; 41: 50-5.

34 O'Brien MP, Gordon JL, Bearden CE, Lopez SR, Kopelowicz A, Cannon TD. Positive family environment predicts improvement in symptoms and social functioning among adolescents at imminent risk for onset of psychosis. Schizophr Res 2006; 81: 269-75.

35 Grice SJ, Kuipers E, Bebbington P, Dunn G, Fowler D, Freeman D, et al. Carers' attributions about positive events in psychosis relate to expressed emotion. Behav Res Ther 2009; 47: 783-9.

36 Veltman A, Cameron Jl, Stewart DE. The experience of providing care to relatives with chronic mental illness. J Nerv Ment Dis 2002; 190: 108-14.

37 Chen FP, Greenberg JS. A positive aspect of caregiving: the influence of social support on caregiving gains for family members of relatives with schizophrenia. Community Ment Health J 2004; 40: 423-35.

38 Bertrando P, Beltz J, Bressi C, Clerici M, Farma T, Invernizzi G, et al Expressed emotion and schizophrenia in Italy. A study of an urban population. Br J Psychiatry 1992; 161: 223-9.

39 Ivanovic M, Vuletic Z, Bebbington P. Expressed emotion in the families of patients with schizophrenia and its influence on the course of illness. Soc Psychiatry Psychiatr Epidemiol 1994; 29: 61-5.

40 Lopez SR, Hipke KN, Polo AJ, Jenkins JH, Karno M, Vaughn C, et al. Ethnicity, expressed emotion, attributions, and course of schizophrenia: family warmth matters. J Abnorm Psychol 2004; 113: 428-39.
41 Breitborde NJK, Lopez SR, Wickens TD, Jenkins JH, Karno M. Toward specifying the nature of the relationship between expressed emotion and schizophrenia relapse: the utility of curvilinear models. Int J Methods Psychiatr Res 2007; 16: 1-10

42 Birchwood M, Cochrane R. Families coping with schizophrenia - coping styles, their origins and correlates. Psychol Med 1990; 20: 857-65.

43 Scazufca M, Kuipers E. Coping strategies in relatives of people with schizophrenia before and after psychiatric admission. Br J Psychiatry 1999; 174: $154-8$.

44 Barrowclough C, Parle M. Appraisal, psychological adjustment and expressed emotion in relatives of patients suffering from schizophrenia. Br J Psychiatry 1997; 171: 26-30.

45 Lazarus RS, Folkman S. Stress Appraisal and Coping. Springer, 1984

46 Magliano L, Fadden G, Economou M, Held T, Xavier M, Guarneri M, et al. Family burden and coping strategies in schizophrenia: 1-year follow-up data from the BIOMED I study. SOC Psychiatry Psychiatr Epidemiol 2000; 35 : 109-15.

47 Barrowclough C, Tarrier N. Families of Schizophrenic Patients: Cognitive Behavioural Intervention. Chapman \& Hall, 1992.

48 Leff J, Kuipers E, Lam D. Family Work for Schizophrenia: A Practical Guide (2nd edn). Gaskell, 2002

49 Magliano L, Fiorillo A, De Rosa C, Malangone C, Maj M. Family burden in long-term diseases: a comparative study in schizophrenia vs. physical disorders. Soc Sci Med 2005; 61: 313-22.

50 Gutiérrez-Maldonado J, Caqueo-Urízar A, Kavanagh D. Burden of care and general health in families of patients with schizophrenia. Soc Psychiatry Psychiatr Epidemiol 2005; 40: 899-904.

51 Joyce J, Leese M, Kuipers E, Szmukler G, Harris T, Staples E. Evaluating a model of caregiving for people with psychosis. Soc Psychiatry Psychiatr Epidemiol 2003; 38: 189-95.

52 Magliano L, Fiorillo A, Malangone C, Marasco C, Guarneri M, Maj M, et al. The effect of social network on burden and pessimism in relatives of patients with schizophrenia. Am J Orthopsychiatry 2003; 73: 302-9.

53 Cuijpers $P$. The effects of family intervention on relatives' burden: a meta analysis. J Ment Health 1999; 8: 275-85.

54 National Institute for Health and Clinical Excellence. Schizophrenia (Update). Clinical Guidelines CG82. NICE, 2009 (http://www.guidance.nice.org.uk/ CG82).

55 Pharoah F, Mari J, Rathbone J, Wong W. Family intervention for schizophrenia. Cochrane Database Syst Rev 2006; 4: CD000088.

56 Barrowclough C, Tarrier N, Lewis S, Sellwood W, Mainwaring J, Quinn J, et al. Randomised controlled effectiveness trial of a needs-based psychosocial intervention service for carers of people with schizophrenia. Br J Psychiatry 1999; 174: 505-11.

57 Szmukler G, Kuipers E, Joyce J, Harris T, Leese M, Maphosa W, et al. An exploratory randomised controlled trial of a support programme for carers of patients with a psychosis. Soc Psychiatry Psychiatr Epidemiol 2003; 38: $411-8$.

58 Berglund N, Vahlne JO, Edman A. Family intervention in schizophrenia impact on family burden and attitude. Soc Psychiatry Psychiatr Epidemiol 2003; 38: 116-21.

59 Giron M, Fernandez-Yanez A, Mana-Alvarenga S, Molina-Habas A, Nolasco A, Gomez-Beneyto M. Efficacy and effectiveness of individual family intervention on social and clinical functioning and family burden in severe schizophrenia: a 2-year randomized controlled study. Psychol Med 2010; 40: 73-84.

60 Onwumere J, Kuipers E, Bebbington P, Dunn G, Freeman D, Fowler D, et al. Needs for closure in caregivers of people with psychosis: links with caregiver and patient characteristics. Epidemiol Psichiatr Soc 2010 (in press).

61 Lawrence V, Murray J, Samsi K, Banerjee S. Attitudes and support needs of Black Caribbean, south Asian and White British carers of people with dementia in the UK. Br J Psychiatry 2008; 193: 240-6.

62 Breitborde N, Lopez S, Chang C, Kopelowicz A, Zarate R. Emotional overinvolvement can be deleterious for caregivers' health. Soc Psychiatry Psychiatr Epidemiol 2010; 44: 716-23.

63 Leff J, Vaughn C. Expressed Emotion in Families. Guilford, 1985.

64 Bentsen H, Notland TH, Munkvold OG, Boye B, Ulstein I, Bjorge H, et al. Guilt proneness and expressed emotion in relatives of patients with schizophrenia or related psychoses. Br J Med Psychol 1998; 71: 125-38.

65 Peterson EC, Docherty NM. Expressed emotion, attribution, and control in parents of schizophrenic patients. Psychiatry 2004; 67: 197-207.

66 Watson PWB, Garety PA, Weinman J, Dunn G, Bebbington PE, Fowler D, et al. Emotional dysfunction in schizophrenia spectrum psychosis: the role of illness perceptions. Psychol Med 2006; 36: 761-70. 
67 Barrowclough C, Tarrier N, Humphreys L, Ward J, Gregg L, Andrews B. Self-esteem in schizophrenia: relationships between self-evaluation, family attitudes, and symptomatology. J Abnorm Psychol 2003; 112: 92-9.

68 Stengard E. Caregiving types and psychosocial well-being of caregivers of people with mental illness in Finland. Psychiatr Rehab J 2002; 26 : 154-64.

69 Bebbington PE, Bhugra D, Brugha T, Singleton N, Farrell M, Jenkins R, et al. Psychosis, victimisation and childhood disadvantage. Evidence from the second British National Survey of Psychiatric Morbidity. Br J Psychiatry 2004; 185: $220-6$.
70 Garety PA, Fowler DG, Freeman D, Bebbington P, Dunn G, Kuipers E. Cognitive-behavioural therapy and family intervention for relapse prevention and symptom reduction in psychosis: randomised controlled trial. Br J Psychiatry 2008; 192: 412-23.

71 O'Brien MP, Zinberg JL, Ho L, Rudd A, Kopelowicz A, Daley M, et al. Family problem solving interactions and 6-month symptomatic and functional outcomes in youth at ultra-high risk for psychosis and with recent onset psychotic symptoms: a longitudinal study. Schizophr Res 2009; 107: 198-205

72 Kuipers L, Bebbington PE. Relatives as a resource in the management of functional illness. Br J Psychiatry 1985; 147: 465-70.

\section{extra}

\section{Ethnic minorities and mental health services: developing a more sustainable approach}

\section{Ovais F. Badat}

Over the past 20 years, it has been encouraging to see the interest in minority groups' mental health. When efforts to investigate or understand certain groups are met with resistance, observers are often tempted to be apologist in stance: the particular group may not have a culture of discussing mental health issues, or it is proffered that the stigma of mental health problems within the group is too great to allow transparent investigation and approach.

In my particular community (a mixture of Indian and West Pakistani economic and political migrants), we are a little amused at the proliferation of so-called services purporting to want to come to our aid. It would seem that every surgery, every government website, and every White worker is nervously brandishing as many ethnic cues as possible, all assertively trained-up on 'ethnic awareness'.

Every ethnic community also has its busybodies: there are people from within who regularly proclaim themselves as being guides or conduits to understanding 'our people'. They spend their time running around from one ethnically diverse, politically sympathetic meeting to another, often just keeping themselves in a position of purpose. We know who they are in our community, and they often do not get much respect from us because they are the opinionated ones who are better dealt with by simply humouring them.

There are several problems with too much adjustment being made by the host country. First, one cannot argue with the fact that an old White man, who may have fought for this country, is upset because he cannot get around or go out whereas his immigrant neighbour, a man of colour who is regularly offered free recreational bus and has a translator on hand to help him along. Although this man is getting the better service, it would seem that his White counterpart, and the wider White community, may be justifiably aggrieved at this over-swinging of the pendulum.

Second, minority communities can become entrenched, and perhaps a little disabled, in a culture of expectation and entitlement. In alternative times, they may have generated their own means of self-sufficiency and moral policing, much like the vibrant immigrant groups in America.

Third, there is the danger in the denting of the communities pride because of all the well-intentioned but overbearing wellwishing. Put succinctly and brutally, we have a proud, functional, complete culture; we acknowledge and try to accomplish the need to become part of British life, if only the British would allow us the breathing space to do so.

Finally, within every community there are the unfortunate elements who will exploit the cultural card. The media rightly bay for blood on news that a Muslim man gets let off a speeding ticket in court because he claims he was late for prayers at the mosque. He knows he is wrong; he should not have sped. But he has played the race/culture card; he has escaped justice under a smokescreen of British apologism. He failed to take responsibility, but he did lean on an open door.

The world of correspondence and counter-correspondence is sharp; I have absolutely no wish to set back all the good work done by those working in the field of minorities' general or mental health. Since this is a strong opinion piece, however, I ventured to state that there is a certain fatigue generated among us as ethnic minorities about the tawdry policies and lazy theories concerning how we manage or more frequently mismanage our mental health.

What to do? Effective integration demands the need for a compensated integration by the immigrant groups arriving to live in the UK; it would be remiss and destructive of them not to do so. Ethnic minority communities could be educated about how health professionals work rather than the other way round; people could be encouraged to expedite their understanding of the western models and management of illness. This is one way in which future generations can feel the benevolent but assertive pull of their host country. In turn, they can also feel more empowered to communicate with Western healthcare professionals in a way that they know they will be understood.

We are British, and by silent majority, integrating in a slow, but steady way. In the translated and blunt words of my grandmother, who arrived here by steamer in 1967 and who, by virtue of not needing to, still cannot speak a word of English: 'It is amazing that they help us so closely. We came to their country, and we are the guests; we must be proud but also give something back'.

Declaration of interest:

O.F.B. born in UK, 1975. Parents and family of mixed Indian and Pakistani origin, immigrated to UK 1967. 